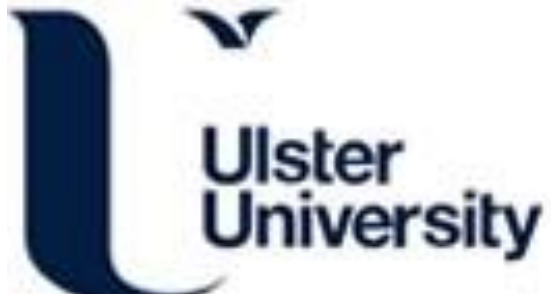

\section{A pilot randomised controlled trial (RCT) investigating the effectiveness of reflexology for managing pregnancy low back and/or pelvic pain}

Close, C., Sinclair, M. ., McCullough, J., Liddle, D., \& Hughes, C. (2015). A pilot randomised controlled trial (RCT) investigating the effectiveness of reflexology for managing pregnancy low back and/or pelvic pain. Complementary Therapies in Clinical Practice, 23, 117-124. https://doi.org/10.1016/j.ctcp.2015.05.002

Link to publication record in Ulster University Research Portal

\section{Published in:}

Complementary Therapies in Clinical Practice

Publication Status:

Published (in print/issue): 11/05/2015

DOI:

10.1016/j.ctcp.2015.05.002

\section{Document Version}

Author Accepted version

\section{General rights}

Copyright for the publications made accessible via Ulster University's Research Portal is retained by the author(s) and / or other copyright owners and it is a condition of accessing these publications that users recognise and abide by the legal requirements associated with these rights.

\section{Take down policy}

The Research Portal is Ulster University's institutional repository that provides access to Ulster's research outputs. Every effort has been made to ensure that content in the Research Portal does not infringe any person's rights, or applicable UK laws. If you discover content in the Research Portal that you believe breaches copyright or violates any law, please contact pure-support@ulster.ac.uk. 
A pilot randomised controlled trial (RCT) investigating the effectiveness of reflexology for managing pregnancy low back and/or pelvic pain

Ciara Close, Marlene Sinclair, Julie Mc Cullough, Dianne Liddle, Ciara Hughes

\begin{abstract}
Many pregnant women with LBPP use pain medications to manage this pain, much of which is self-prescribed and potentially harmful. Therefore, there is a need to find effective nonpharmacological treatments for the condition. Reflexology has previously been shown to help nonspecific low back pain. Therefore; a pilot RCT was conducted investigating reflexology in the management of pregnancy-LBPP.
\end{abstract}

90 primiparous women were randomised to either usual care, a reflexology or footbath intervention.Primary outcome measures were; the Pain Visual Analogue Scale (VAS). 64 women completed the RCT; retention rates for the reflexology group were $80 \%$, usual care group $83.33 \%$ and footbath group $50 \%$. The reflexology group demonstrated a Clinically Important Change $(\mathrm{CIC})$ in pain frequency $(1.64 \mathrm{~cm})$. Results indicate it is feasible to conduct an RCT in this area, although a footbath is an unsuitable sham treatment. Reflexology may help manage pregnancy-LBPP; however a fully powered trial is needed to confirm this. 


\subsection{Introduction}

Low back pain is typically experienced by over two thirds of pregnant women and pelvic pain by almost one fifth [1]. Low back and/ or pelvic pain (LBPP) can have significant consequences on women's health and well-being, affecting their ability to walk, sleep, work and increasing their risk of depression $[2,3,4]$.

Low back and pelvic pain are frequently considered together due to pregnant women's inability to distinguish between the two and the limited clinical tests available for health professionals to distinguish between them [5]. Currently, there is no clinical guideline for managing the problem and this has led to pregnant women using a wide range of treatment strategies, some of which may pose health risks to the fetus. A recent survey indicated that most women with pregnancy-LBPP use pain medications much of which is self-prescribed [6]. This is concerning particularly as pregnant women are recommended to avoid pain medications where possible and advised only to use medications under health professional supervision. In this survey it was revealed that opiates were among the most frequently used pain medications for pregnancy-LBPP, even though these drugs have been shown to have specific risks to the health of the mother such as dependence as well as increasing the risk of spina bifida for the baby $[7,8]$. These findings suggest the need for more research into potential non-pharmacological management strategies for pregnancy -LBPP.

CAM is popular with pregnant women for managing a range of pregnancy ailments including LBPP. Pregnant women report various reasons for making their decision to use CAM these include; a desire to increase control over the child bearing experience and the belief that these treatments offer a safer alternative to pharmacological treatments $[9,10]$. Pregnant women's belief in these treatments is evident in the fact that the majority of CAM is selffunded with only a few maternity hospitals offering such provisions. There are many forms 
of CAM which pregnant women chose to use, popular choices include osteopathy, chiropractic and reflexology [6]. Despite the popularity of CAM and its use for pregnancy LBPP, research into the use of CAM for managing pregnancy-LBPP is restricted. A recent systematic review on CAM in the management of pregnancy- LBPP found limited evidence to support CAM use for this pregnancy complaint, due to lack of available studies in the area, studies with small sample sizes and other methodological issues [11]. This review identified a small number of studies using acupuncture, osteopathy and chiropractic treatments but none on reflexology.

Reflexology is a CAM therapy which can be defined as:

"The use of a sophisticated system of touch, usually on the feet.....in which the area being massaged is thought to correspond to a map of the whole body," [12].

Even though reflexology has not been investigated for managing pregnancy LBPP it has been reported to be a popular choice of CAM for pregnant women for treating pregnancy various pregnant ailments. Further to this, of the few maternity hospitals in the United Kingdom which offer CAM treatments for pregnancy complaints reflexology is one of the most frequently provided treatments $[6,13]$.

Furthermore, there is evidence of effectiveness for reflexology for managing non-specific low back pain (LBP) $[14,15]$. A pilot RCT of 15 adults, with LBP randomised to reflexology or sham reflexology found a median reduction of $1.9 \mathrm{~cm}$ on the pain VAS in the reflexology group compared to an increase of $0.1 \mathrm{~cm}$ in the sham group at the end of the intervention [14]. In a double blind RCT randomising 50 female and male nurses with LBP to a reflexology or non-specific massage intervention found that those in the reflexology group had a significantly higher reduction in the intensity of their pain compared to those in the nonspecific massage group [15]. 
The evidence of effectiveness for reflexology in managing non-specific LBP, its nonpharmacological nature combined with the popularity of this treatment in the pregnant population indicated potential merit in researching this treatment for pregnancy- LBPP.

Therefore, this study set out to determine if it was possible to conduct an RCT investigating the effectiveness of reflexology as an addition to usual care for pregnancy LBPP. The study objectives were to investigate recruitment, compliance and retention rates along with the logistics of providing the interventions in a maternity setting and the sensitivity of the outcomes measures (OM's) to detect changes.

\subsection{Materials and Methods}

2.1 Inclusion/ exclusion criteria

Ethical approval was received from the Office of Research Ethics Northern Ireland in July 2012 (reference number 12/NI/0052). Table 1 shows study inclusion and exclusion criteria (next page). 
Table 1: RCT inclusion and exclusion criteria

\begin{tabular}{|c|c|}
\hline Inclusion Criteria & Exclusion Criteria \\
\hline First time pregnant women & Women pregnant with more than one baby \\
\hline$\geq 18$ years of age & Smokers \\
\hline $\begin{array}{l}\text { Presence of low back pain and/or pelvic } \\
\text { pain (assessed prior to active participation) }\end{array}$ & Women with neurological diseases \\
\hline 26-29 weeks gestation & Deep Vein Thrombosis (DVT) sufferers \\
\hline \multirow[t]{11}{*}{$\begin{array}{l}\text { Able to understand written and verbal } \\
\text { English }\end{array}$} & Fungal foot infections or verrucae \\
\hline & Currently using CAM therapies \\
\hline & Placenta Previa Grade 3 or 4 \\
\hline & Already participating in a research study \\
\hline & $\begin{array}{l}\text { Any serious spinal pathology e.g. cancer, } \\
\text { Cauda Equina, infection in the spine? }\end{array}$ \\
\hline & Previous road traffic accident \\
\hline & $\begin{array}{l}\text { Previous surgery to the hip, back or pelvic } \\
\text { region }\end{array}$ \\
\hline & Inflammatory arthritis \\
\hline & Diabetes/Gestational diabetes \\
\hline & Cardiac related problems \\
\hline & $\begin{array}{l}\text { Women whom the midwife deems unable to } \\
\text { participate }\end{array}$ \\
\hline
\end{tabular}




\subsection{Recruitment}

Women were recruited from ante-natal clinics in the Ulster Maternity Unit, in Northern Ireland between July 2012 and September 2013 which has an annual birth rate of approximately 4000 . Women meeting the inclusion criteria were identified by the midwife, at 20-22 weeks gestation when they attended for a foetal anomaly scan. The LBPP inclusion criterion was applied later as participation didn't begin until a later gestation. Therefore, women were invited to take part in the RCT at 20-22 weeks irrespective of whether they had LBPP at this time point or not. Inviting women even if they did not have LBPP was seen as an important way to ensure that all eligible women could participate in the study, given that it was possible for women to develop LBPP between the initial invitation to participate (20-22 weeks) and active participation in the RCT (26-29weeks). Only inviting women who had LBPP at 20-22weeks could have severely reduced recruitment to this study and given that the average number of week's gestation at the time of onset of pregnancy-LBPP has been reported to be 22 weeks, many women may not have been experiencing LBPP at 20-22 weeks when they were initially invited to participate in the RCT but may have developed this pain later in their pregnancy [16].

At the initial recruitment point women were provided with a verbal overview, patient information sheet and consent form by the researcher. Interested women contacted the researcher before 29 weeks gestation and were screened for eligibility over the telephone by the researcher.

\subsection{Randomisation}

At 26-29 weeks gestation women attended the hospital for their first study appointment, completing baseline outcome measures (OM's), a paper-based physiotherapy questionnaire, and urinalysis. Before randomisation participants indicated expectations of helpfulness for reflexology and footbaths for reducing pregnancy-LBPP. Women were then given a sequentially, numbered opaque sealed, envelope containing details of their group allocation. The randomization schedule was drawn up using computer generated block randomization before study commencement by an independent statistician. To conceal the 
intervention under investigation the research study was referred to as "The CAM in

Pregnancy Trial".

Women in the study continued to receive the usual care for pregnancy-LBPP provided within the maternity unit. Usual care participants received no additional intervention during the study; however they were offered a free reflexology treatment after the study period.

\subsection{Interventions}

This RCT had three different groups, a reflexology group, a footbath group and a usual care group. Footbath and reflexology participants received a 30 minute treatment weekly, for six weeks. The same music, lighting and location in the hospital were used for both treatments. Footbaths were based on a similar regimen used in a study investigating the effectiveness of footbaths on fatigue and insomnia in cancer patients [17]. Footbaths consisted of the feet being sub-emerged in a footbath while the participant sat upright in a padded chair using cushions to support their neck and back. The footbath simply contained some coloured stones for aesthetic purposes and water only, which was filled up to ankle level and maintained at approximately 41 degrees. This was done by the researcher probing the water with a thermometer at ten minute intervals and topping it up accordingly. The footbaths were performed by one of two researchers adhering to the same regimen throughout.

Reflexology treatments were performed by a qualified maternity reflexologist based primarily on the work of Sue Enzer and Denise Tiran following a pragmatic approach focusing on the key reflex points corresponding to the back or pelvis $[18,19]$. Reflexology treatments were completed in a supine position at an approximate 30 degree angle with a pillow supporting the neck. Table 2 outlines the steps of the reflexology protocol. 
Table 2: The reflexology protocol

\begin{tabular}{|c|c|}
\hline 1 & Greet the feet and visual inspection \\
\hline 2 & Gentle heel/leg stretch \\
\hline 3 & Oil feet and massage right then left foot using effleurage and stroking \\
\hline 4 & Cover left foot and begin reflexology on right foot first as follows \\
\hline 5 & Ankle rotations \\
\hline 6 & Ankle and lower leg massage-musculature of thigh and pelvis \\
\hline 7 & Spinal stretch \\
\hline 8 & Caterpillar walk from kidney to bladder \\
\hline 9 & $\begin{array}{l}\text { Open up ribs; tops of feet by applying pressure with the length of the thumbs side by } \\
\text { side and spreading apart }\end{array}$ \\
\hline 10 & Open up lungs-soles of feet \\
\hline 11 & Toe tweaks and toe rotations- stimulation of head and neck \\
\hline 12 & Thumb press in stripes on big toe pad \\
\hline 13 & Wring the foot by grasping the foot in both hand and gently imitate a wringing action \\
\hline 14 & Scrape, using the crooked index finger, across neck reflex \\
\hline 15 & Caterpillar and stimulation of reflexes from head to coccyx \\
\hline 16 & Sedation of lower back reflex \\
\hline 17 & Sedate symphysis pubis reflex-around ankle bone on inside of feet \\
\hline 18 & $\begin{array}{l}\text { Caterpillar and sedate reflexes of bones and muscles of pelvis and pelvic floor-around } \\
\text { edge of heels }\end{array}$ \\
\hline 19 & Caterpillar across and down pelvic region reflex on gross heel \\
\hline 20 & Sedate "black holes" symphysis pubis reflex on top of foot \\
\hline 21 & Sedate sacroiliac joint reflex-posterior to ankle bone on outside of feet \\
\hline 22 & Caterpillar up leg and thigh reflexes \\
\hline 23 & Pressures to knee and elbow reflexes \\
\hline 24 & Caterpillar up arm, shoulder and scapula reflexes \\
\hline 25 & Caterpillar across trapezium reflexes \\
\hline 26 & Pressures to jaw and teeth reflexes \\
\hline 27 & Gently effleurage to breast reflex on top of foot \\
\hline 28 & Stimulation of abdominal musculature reflexes-backwards of rib area on tops of feet \\
\hline 29 & $\begin{array}{l}\text { Gentle caterpillar across stomach, duodenum and pancreas, where the participant has } \\
\text { indicated that they have heartburn use gentle sedation to these reflexes. }\end{array}$ \\
\hline 30 & Caterpillar along bowel reflex \\
\hline 31 & $\begin{array}{l}\text { Gentle pressure to liver and gallbladder reflexes (right foot) and heart and spleen (left } \\
\text { foot) }\end{array}$ \\
\hline 32 & Wring foot \\
\hline 33 & Massage foot using effleurage strokes \\
\hline 34 & Lymphatic drainage using ling flowing fingertip pressure from lower leg to toes \\
\hline 35 & Simultaneous diaphragm hold until energy is felt and sweep, repeat three times \\
\hline
\end{tabular}




\begin{tabular}{|l|l|}
\hline $\begin{array}{l}\text { Step } \\
\text { number }\end{array}$ & Outline of step \\
\hline 36 & Simultaneous solar plexus hold \\
\hline 37 & Gentle hold over uterus reflex with cupped hands \\
\hline 38 & Effleurage from ankle to toe \\
\hline 39 & Towel feet and stroke over \\
\hline 40 & Hold feet gently and release \\
\hline
\end{tabular}

\subsection{Outcome measures}

At the initial and final study appointment women completed primary and secondary OM's.

The primary OM's were the pain Visual Analogue Scale (VAS) for intensity and frequency of LBPP. Secondary OM's included; the Roland Morris Disability Questionnaire (RMDQ) the Pregnancy Mobility Index (PMI) and the S-subscale of the State Trait Anxiety Inventory (STAI). Treatment expectations and treatment helpfulness were also assessed on a 0-10 VAS scale, $0=$ no help at all and $10=$ very helpful.

At treatments, reflexology and footbath participants were questioned about interventions used in the past week for managing LBPP and completed the VAS for pain intensity and frequency. Usual care participants completed the VAS questionnaires weekly at home and kept diary of the treatments used to manage their LBPP. Text messages were send throughout the study to remind this group to complete study paperwork.

\subsection{Focus groups}

Focus groups were conducted as an additional part of this research with participants of the RCT complying with the protocol, full details are reported elsewhere [20]. The focus groups 
primary aim was exploring women's experiences of pregnancy- LBPP. However, additional questions were asked about women's experience of the RCT.

\subsection{Data analysis}

The Statistical Package for Social Sciences (SPSS) version 21 was used for data analysis. This study did not test for statistical differences between groups as it was not powered to detect these. Therefore, analysis on the effectiveness of reflexology on pregnancy- LBPP was based on clinically important change $(\mathrm{CIC})$, which is positive change felt by the individual providing a degree of symptom relief [21].

For pain intensity and frequency $\mathrm{CIC}$ is considered as $1.5 \mathrm{~cm}$ on the pain VAS [22], three points on the RMDQ [23] and 30\% change from baseline on the PMI [22]. In this paper we present descriptives only including frequencies, means and standard deviations.

A modified Intention to treat analysis was used for outcome analysis; this meant analysing only participants who completed four or more study weeks and provided baseline and end of intervention data. Missing observations within these participants were imputed using the last number carried forward method.

\subsection{Results}

\subsection{Participants}

428 women were invited to participate in the RCT, this included women with and without LBPP with the notion of trying to ensure that all women had knowledge about they study should they develop LBPP later in their pregnancy. However, 52 of these were automatically excluded mainly as they were participating in another study, the remainder did not participate in the study for reasons including no LBPP and travel issues. 
In total 90 pregnant women enrolled in the RCT. 30 participants were randomised to either a; reflexology, footbath or usual care group with 64 participants completing the study (see Fig. 1). 
Figure 1: Flow and retention diagram of participants progress throughout the pilot RCT

\section{Enrolment}
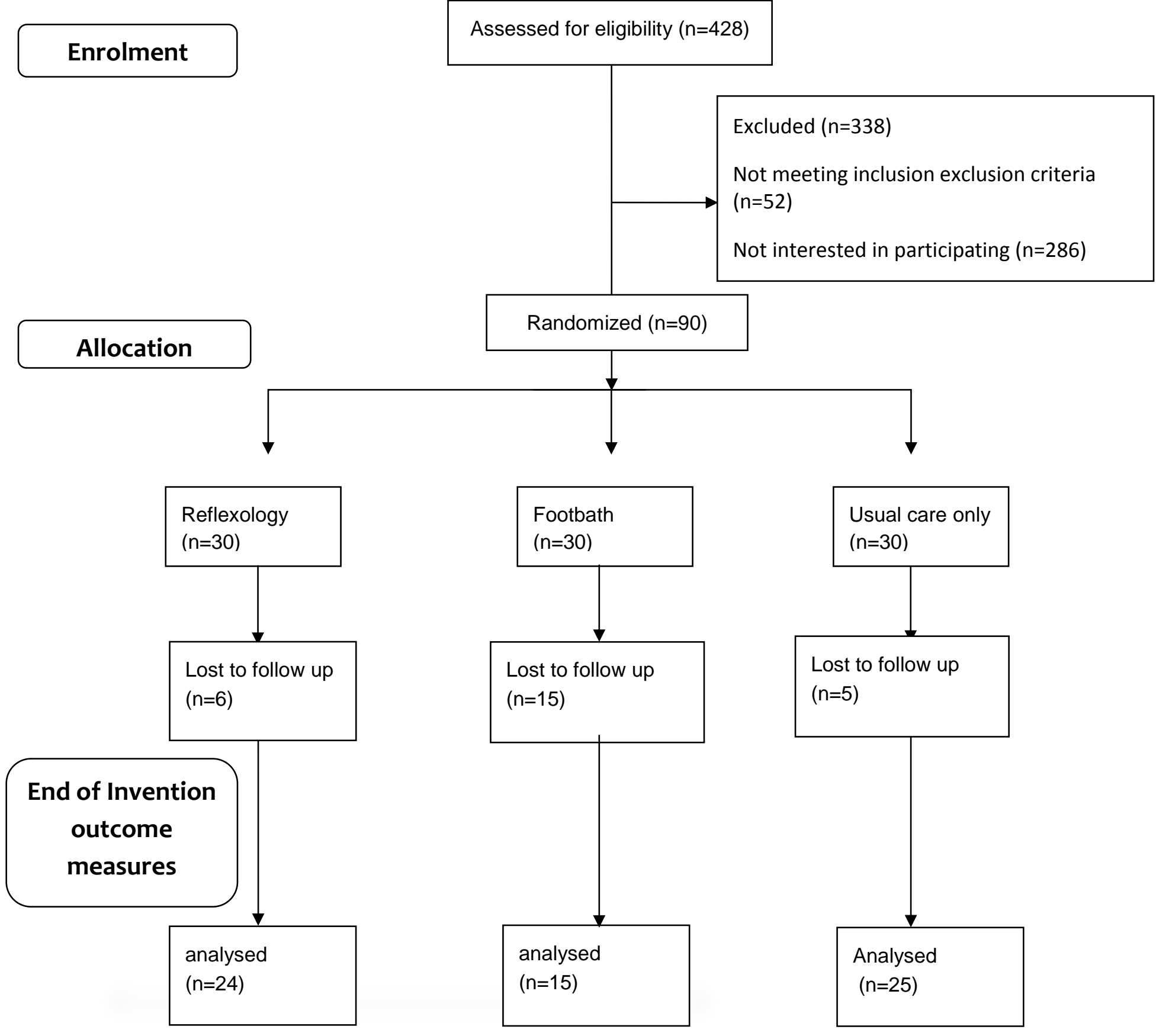

Those completing the study included 24 reflexology participants, 25 usual care participants and 15 footbath participants. The mean age of participants completing the study in the reflexology group was 30.7 years, in the footbath group was 32.3 years and in the usual care group was 30.1 years. Most women were in professional occupations (table 3). 
Table 3: Demographics by group allocation for the 64 women who complied with the study protocol and were included in MITT analysis, along with standard deviations in brackets

\begin{tabular}{|c|c|c|c|}
\hline & $\begin{array}{l}\text { Reflexology } \\
(n=24)\end{array}$ & $\begin{array}{l}\text { Footbath } \\
(n=15)\end{array}$ & $\begin{array}{l}\text { Usual care } \\
(n=25)\end{array}$ \\
\hline $\begin{array}{l}\text { Mean Age } \\
\text { (years) }\end{array}$ & $30.7(3.64)$ & $32.3(3.15)$ & $30.1(5.65)$ \\
\hline $\begin{array}{l}\text { Mean baseline gestation } \\
\text { (weeks) }\end{array}$ & $27(0.98)$ & $27(0.93)$ & $27.08(0.86)$ \\
\hline $\begin{array}{l}\text { Mean end of intervention gestation } \\
\text { (weeks) }\end{array}$ & $33.58(1.25)$ & $33.53(1.06)$ & $32.04(1.26)$ \\
\hline BMI & $26.11(3.68)$ & $25.13(4.10)$ & $25.66(4.16)$ \\
\hline \multirow[t]{4}{*}{ Socio economic status } & $1=U / E$ & $0=U / E$ & $1=U / E$ \\
\hline & 12-PRO & $7=P R O$ & $14=P R O$ \\
\hline & $8=S S$ & $5=S S$ & $7=S S$ \\
\hline & $3=U S$ & $3=U S$ & $3=U S$ \\
\hline \multirow[t]{2}{*}{ CAM experience } & Yes $=23$ & Yes $=11$ & Yes $=20$ \\
\hline & $\mathrm{No}=1$ & $\mathrm{No}=4$ & $\mathrm{No}=5$ \\
\hline \multirow[t]{3}{*}{ Type of pain } & LBP $=13$ & $L B P=8$ & $\mathrm{LBP}=13$ \\
\hline & $P P=1$ & $P P=0$ & $P P=1$ \\
\hline & LB \& $P P=10$ & LB\& $P P=7$ & LB\& $P P=11$ \\
\hline \multirow[t]{2}{*}{ Occurrence of LBPP pre-pregnancy } & Yes=14 & Yes $=5$ & Yes $=11$ \\
\hline & $\mathrm{No}=10$ & No $=10$ & $\mathrm{No}=14$ \\
\hline
\end{tabular}

Key to abbreviations: CAM-Complementary and Alternative Medicine; BMI-body mass index; U/E-unemployed; PRO-Professional; SS-Semi-skilled; US-unskilled; LBPP-Low back and/ or pelvic pain; LBP-Low back pain, Pelvic Pain-PP 


\subsection{Outcome measures}

Table 4 shows scores for LBPP OM's completed during the study and figure 2 shows the number of women in each group achieving CIC for the LBPP OM's. 
Table 4: Pain VAS, RMDQ, PMI, STAI scores-Means, standard deviations and score changes

\begin{tabular}{|c|c|c|c|}
\hline & Reflexology & Footbath & Usual care \\
\hline Pain Vas week 0 LBPP & $7.05(2.36)$ & $5.65(2.27)$ & $5.86(2.54)$ \\
\hline \multicolumn{4}{|l|}{ FREQUENCY } \\
\hline Pain VAS week 6 LBPP & $5.41(2.80)$ & $6.13(2.85)$ & $5.50(2.80)$ \\
\hline \multicolumn{4}{|l|}{ FREQUENCY } \\
\hline Change & $-\quad 1.64$ & +0.48 & -0.36 \\
\hline Pain VAS week 0 LBPP & $5.81(2.02)$ & $4.68(2.31)$ & $5.12(2.19)$ \\
\hline \multicolumn{4}{|l|}{ INTENSITY } \\
\hline Pain VAS week 6 LBPP & $5.14(2.65)$ & $5.63(2.26)$ & $5.33(2.69)$ \\
\hline \multicolumn{4}{|l|}{ INTENSITY } \\
\hline Change & -0.67 & +0.95 & +0.21 \\
\hline RMDQ week 0 & $9.67(3.91)$ & $9.67(3.98)$ & $9.04(4.96)$ \\
\hline RMDQ week 6 & $8.29(5.23)$ & $11.13(5.13)$ & $10.21(5.28)$ \\
\hline Change & -1.38 & +1.46 & +1.17 \\
\hline PMI week 0 & $23.29(9.60)$ & $27.13(8.94)$ & $22.60(13.16)$ \\
\hline PMI week 6 & $25.88(11.88)$ & $29.73(11.50)$ & $29.44(14.18)$ \\
\hline Change & +2.59 & +2.6 & +6.84 \\
\hline STAI week 0 & $43.46(5.18)$ & $44.2(3.84)$ & 45.72 (4.09) \\
\hline STAI week 6 & $44.92(4.12)$ & 45.07 (3.33) & $45.72(4.69)$ \\
\hline Change & +1.46 & +0.87 & Nil \\
\hline
\end{tabular}


Figure 2: Percentage of women in each group who showed a Clinically Important Change $(\mathrm{CIC})$ for a range of LBPP outcome measures over the study period

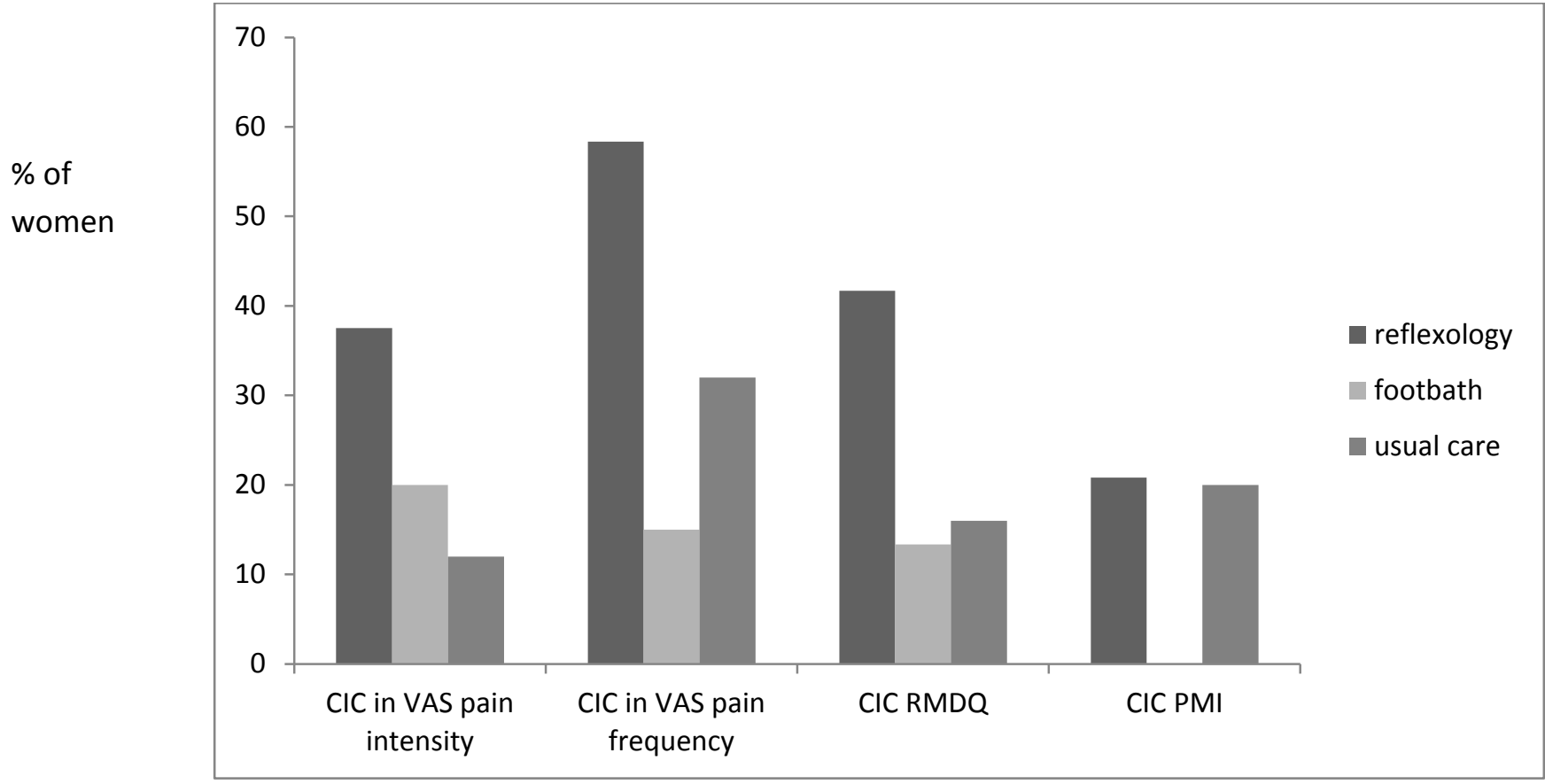

$\mathrm{ClC}$ by outcome measure 
Mean LBPP frequency score for the reflexology group improved by $1.64 \mathrm{~cm}$ from the start to end of intervention. This reduction was greater than the minimum change of $1.5 \mathrm{~cm}$ needed on the pain VAS to demonstrate a CIC. There was a slight increase of $0.45 \mathrm{~cm}$ in LBPP frequency in footbath participants and a minimal decrease in LBPP frequency of $0.36 \mathrm{~cm}$ on the VAS in the usual care participants. More women in the reflexology group (58\%) achieved a CIC in VAS pain frequency compared to the other two groups.

The mean LBPP VAS for pain intensity reduced slightly in reflexology participants and increased slightly in the usual care group. There was almost a $1 \mathrm{~cm}$ increase on the VAS for pain intensity for the footbath group. More women in the reflexology group (37.5\%) achieved a CIC in VAS for pain intensity for LBPP compared to the other two groups.

RMDQ scores decreased in the reflexology group and increased in other groups. Reductions in RMDQ scores in the reflexology group did not reach a clinically important level. However, more women in the reflexology group (42\%) had a mean CIC in the RMDQ scores compared to other groups.

PMI scores increased in all groups, increasing similarly in the reflexology (2.59) and (2.60) footbath groups. However, a much bigger increase (6.44) was observed in PMI scores for usual care participants. A similar percentage of women in the reflexology (21\%) and usual care groups (20\%) had a CIC in PMI scores; no women in the footbath group had a $\mathrm{CIC}$ in PMI scores. 
There was little change in STAI scores from the start to the end of the study period in all groups.

More reflexology participants used pain medications $(50 \%)$ and yoga $(21 \%)$ to manage LBPP as an addition to reflexology. More footbath participants used physiotherapy (20\%), Pilates (33\%) and massage (20\%) in addition to the footbath.

At baseline women had higher expectations of the helpfulness of reflexology $(6.92 / 10)$ for reducing LBPP compared with footbaths (4.57/10). Reflexology participants reported finding reflexology more helpful for reducing their LBPP compared to footbath participants (6.92/10 compared with 3.65/10)

\subsection{Adverse effects}

No adverse outcomes were reported throughout the study. However, one reflexology participant had a stillbirth at 41 weeks gestation and another woman gave birth to a baby with a known cardiac problem that died three weeks after birth. Both events were viewed by clinical staff in the maternity unit to be unrelated to this study.

\subsection{Feasibility}

Retention rates for the reflexology and usual care groups were $80 \%$ and $83 \%$ respectively. $50 \%$ of women randomised to the footbath group dropped out before the end of the intervention. Common reasons for dropping out were the development of a health condition, unhappy with treatment allocation and work commitments.

24 /30 reflexology participants attended four or more treatments compared to just $15 / 30$ footbath participants. 10/30 footbath participants attended for just one treatment 
compared to just $3 / 30$ reflexology women. $25 / 30$ usual care women provided data for at least four weeks.

\subsection{Focus groups}

14 women attended three focus groups. This included eight reflexology participants, four footbath participants and two usual care participants. Quotes will be presented as follows participant number (PN), age, intervention group footbath (FB), reflexology (R) Usual Care (UC) and type of pain low back pain (LBP) Pelvic pain (PP).

Those allocated to footbath and usual care reported being unhappy with their group allocation:

"I was really disappointed I have to admit ... I was gutted because I wanted to see if the reflexology would help,"

\section{PN8, 35 UC LB\&PP}

The majority of women reported that they took part for the hope of getting reflexology:

"Potentially getting reflexology then yes absolutely...I had nothing to lose,"

\section{PN14, 30 R LB \& PP}

Focus groups drew attention to the fact that several women had been informed by staff that reflexology was the treatment of interest:

"I was told it was reflexology and it would help your back pain the midwife didn't actually say to me at that point there are three options,"

\section{PN8, 35 UC LBP \& PP}


Women who received reflexology displayed very positive attitudes towards reflexology, discussing improvements following treatment:

"I had reflexology and it was brilliant it really really helped...I think after two session I was off the crutches and able to kind of ...move a bit better," (PN5, 26 R LBPP)

\subsection{Discussion}

This is the first RCT to investigate reflexology in the management of pregnancy- LBPP and to find improvements in LBPP OM's. We have demonstrated it is possible to recruit pregnant women into an RCT investigating reflexology for pregnancy -LBPP and to deliver CAM treatments as part of an RCT in a maternity hospital. In 14 months, 90 women were recruited to the study. An Australian researcher took two years to recruit 69 women into a RCT investigating reflexology for pregnancy ankle oedema [24]. Therefore, recruitment into this study was found to be feasible. Overall, attrition rates (28\%) were as expected. Two RCT's of a similar size investigating acupuncture for pregnancy LBP and pelvic pain reported a $28 \%$ and $32 \%$ drop out rate respectively $[25,26]$. Attrition rates were higher for the footbath group than other groups. The Australian reflexology study for ankle oedema also had issues with drop-outs in their control group[24].Low expectations for helpfulness of footbaths and the fact that women reported being fuelled to participate in the study by the prospect of receiving reflexology could explain the high attrition rates and poor compliance with the footbath.

Sham treatments are important in CAM research as a useful way of determining if a CAM treatment is related to the treatment provided or the context in which it is being delivered. 
However, it is important that participants are blinded to the treatment of interest. While ever effort was made to blind women to the treatment of interest in this study, focus group findings would indicate that blinding may not have been successful. Footbaths are used in maternity settings in Japan, for labouring women to facilitate relaxation and to aid a smooth labour process [27]. Therefore, footbaths were chosen as the sham treatment for this study as they provided a relaxing treatment which would control for patient therapist interaction but without additional touching of the feet. For a future trial, the use of sham reflexology may be a more appropriate sham treatment, as it may be easier to blind participants and attrition rates in reflexology studies employing sham reflexology have been acceptable [28]. However, a recent reflexology review highlights that finding an appropriate sham treatment for reflexology without stimulating the feet reflexes may be challenging as even light pressure on the feet may stimulate the reflexes [29]. Several studies using sham reflexology as a comparator for true reflexology found positive effects of both treatments, or smaller differences between groups, [24, and 28] supporting the theory that it is difficult to work with the feet without stimulating the reflexes.

This study demonstrated that it is feasible to use the VAS for pain frequency and Intensity and RMDQ. These OM's are already showing trends and detecting $\mathrm{CIC}$ suggesting they are sufficiently sensitive to detect change within this population. The use of the s- subscale of STAI may not be particularly suitable for assessing reductions in stress associated with reflexology as little changes were detected. However, it is possible that reflexology may reduce pregnancy specific stress and not general stress and a future study may consider assessing the impact of reflexology on pregnancy specific stress. The PMI didn't show any trends in outcomes. This could be due to interpretation of the questions. Woman may have 
found it difficult to separate restrictions their LBPP was causing and what restrictions the actual pregnancy itself is causing due to pregnancy weight gain.

There were trends in improvement in three of the four LBPP OM's assessed for the reflexology participants and a $\mathrm{ClC}$ was achieved for the VAS for frequency of pain in this group. In addition more individual women achieved a CIC for all of the OMs following reflexology than footbath or usual care groups. Any trends in improvement in LBPP OM's as pregnancy progresses are worthy of further exploration as the LBPP literature suggests that pregnancy- LBPP increases as pregnancy advances. A fully powered RCT would be required to be able to determine the true impact of reflexology on pregnancy- LBPP, testing for statistical differences between groups.

While the inability to analyse the present RCT findings for statistically differences impedes on our ability to determine if one treatment is more effective than another, the presence of $\mathrm{CIC}$ is still a notable finding for a subjective condition like LBPP meaning that some patients found a degree of symptom relief. $\mathrm{ClC}$ is a useful tool in back pain treatment used to determine the responsiveness to treatment on an individual basis [30]. It is not always possible to determine statistically significances, as in this present study when sample sizes are too small however; $\mathrm{CIC}$ could be viewed as another method of assessing effectiveness when this is not possible.

The improvements in LBPP OM's following reflexology in this study are supported by other studies $[14,15]$. However, while the available published studies on reflexology for LBP found reflexology performed superior to a sham, both studies also found improvements in the sham groups. These studies possibly demonstrated improvements in LBP in the sham group as both studies employed sham treatments that involved touch. Researchers have suggested that touch can stop pain signals reaching the brain [31]. The footbath and usual care participants simply may not have improved LBPP OM's as they did not receive a treatment involving touch. 
Another possible reason why reflexology participants in our study had better LBPP outcomes could be explained by their more frequent use of pain medications and yoga. While pain medications have not been investigated for their effectiveness for reducing pregnancy -LBPP, it would be expected that they would have some reducing effect [32]. Furthermore, yoga has been shown in two studies to produce statistically significant reductions in pregnancy -LBPP and therefore may have contributed to the improved LBPP outcomes for reflexology participants $[33,34]$. Despite this it is still possible that the application of the reflexology, specifically the stimulation of the back and pelvis reflexes on the feet, caused the improved LBPP outcomes. In order to determine if reflexology is or is not a precision treatment, future studies need to carefully consider the use of an appropriate sham treatment.

Several theories have been suggested as to why reflexology may reduce pain and disability; one popular theory is the beta endorphin release theory. While some researchers claim that this is why reflexology reduces pain [19], this theory was examined in another part of this study by a co-investigator and was not substantiated. The methods and results of this exploration of the beta-endorphin theory as the mechanism of action for reflexology have been described elsewhere [35].

The findings of this present study expand the evidence-base on non-pharmacological and CAM for pregnancy- LBPP, which to date are sparse. Reflexology is a CAM therapy, popular with pregnant women with evidence of effectiveness for non-specific LBP yet until now there has been no data from RCT's investigating the potential effectiveness of reflexology for pregnancy- LBPP. 
Given the positive findings about reflexology for managing pregnancy- LBPP it would be important to undertake a fully powered trial to confirm or disprove these. If future studies provide evidence that reflexology is effective for managing pregnancy-LBPP this may help reduce the use of pain medications for pregnancy- LBPP [6]. This is a priority as there is no robust evidence supporting the use of pain medications safe during pregnancy. Further to this, reflexology if proven effective in future studies may reduce the societal impact of pregnancy- LBPP as well as reducing the personal impact this pain has on women's lives.

\subsection{Limitations}

The primary limitations of this RCT were the use of self-report measures and the small sample size. The small sample size means that it was impossible to analysis RCT data for statistical differences between groups, and therefore we used $\mathrm{CIC}$ as a measure of effectiveness for reflexology. This method of assessing the effectiveness of treatments is not routinely used in RCT's as it is unable to determine if one group is superior to another and this could be considered a limitation of the present study. Another important limitation is the fact that pain frequency was the only $\mathrm{OM}$ to have a $\mathrm{CIC}$ yet for this particular outcome measure reflexology participants started out over one point higher than the other two groups, meaning they had greater scope for improvement in this outcome measure compared with the other groups.

\subsection{Conclusion}

This study has demonstrated that it is possible to conduct an RCT investigating the effectiveness of reflexology on pregnancy-LBPP. It is possible to recruit participants, complete interventions and compliance, retention and OM sensitivity were acceptable. Before reflexology can be considered as a treatment for pregnancy- LBPP, a fully powered trial needs to be conducted. This is important given that the present findings suggesting that reflexology may help improve pregnancy -LBPP. 


\section{Acknowledgments}

The work undertaken in this study was supported by a studentship award provided by the Department of Employment and Learning, Northern Ireland. The authors would like to thank Dr. Paul Slater from the University of Ulster for his statistical advice. 
References

[1] Pennick V and Liddle SD. Interventions for preventing and treating pelvic and back pain in pregnancy. Cochrane Database of Systematic Reviews. 2013 Available online:

http://onlinelibrary.wiley.com/doi/10.1002/14651858.CD001139.pub3/pdf on 13 (accessed 13th October 2014)

[2]Mogren I. Perceived health, sick leave, psychosocial situation, and sexual life in women with low-back pain and pelvic pain during pregnancy. Acta Obstetricia et Gynecologica Scandinavica 2006; 85: 647-656.

[3] Dørheim SK, Bjorvatn B, Eberhard-Gran M. Sick leave during pregnancy: a longitudinal study of rates and risk factors in a Norwegian population, BJOG: An International Journal of Obstetrics \& Gynaecology 2013; 120; 521-530.

[4] Van de Pol G, Brummen HJ, Bruisne HW, Heintz AP, van der Vaart CH. Pregnancy-related pelvic girdle pain in the Netherlands. Acta Obstetricia et Gynecologica Scandinavica 2007; 86(4): 416-22.

[5] Ostgaard HC, Andersson GBJ, Karlsson K. Prevalence of back pain in pregnancy. Spine $1991 ; 16(5): 549-552$.

[6] Sinclair M, Close C, McCullough J EM, Hughes C, Liddle SD. How do women manage pregnancy-related low back and/or pelvic pain? Descriptive findings from an online survey. Evidence Based Midwifery 2014; 12(3): 76-82.

[7] Kennedy D. Analgesics and pain relief in pregnancy and breastfeeding, Australian prescriber 2011; 34: 8-10. 
[8] Broussard CS, Rasmussen SA, Reefhuis J, Friedman JM, Jann MW, Riehle-Colarusso T, Honein M. Maternal treatment with opioid analgesics and risk for birth defects. American Journal of Obstetrics and Gynaecology 2011; 204(4): 314.e1-11.

[9] Mitchell M. Women's use of complementary therapies in pregnancy: a search for holistic wellbeing. Women and Birth 2014; 27. 276-280.

[10] Warriner S, Bryan K, Brown, AM. Women's attitude towards the use of complementary and alternative medicine in pregnancy. Midwifery. 2014.30. 138-143

[11] Close C, Sinclair M, Liddle SD, Madden E, McCullough JEM and Hughes CM. A systematic review investigating the effectiveness of Complementary and Alternative Medicine (CAM) for the management of low back and/or pelvic pain (LBPP) in pregnancy. Journal of Advanced Nursing 2014; Available from:

http://onlinelibrary.wiley.com/doi/10.1111/jan.12360/abstract [Accessed 9th March 2014].

[12] Lett A. Reflex zone therapy for health professionals. Edinburgh: Churchill, Livingstone 2002.

[13] Williams J and Mitchell M. Midwife managers views on the integration of complementary therapies in the maternity services. Complementary Therapies in Clinical Practice 2007; 13 (20): 129-135. 
[14] Quinn, F., Baxter, G.D. and Hughes, C.M. Complementary therapies in the management of low back pain: A survey of reflexologists. Complementary Therapies in Medicine 2008; 16, 11-14.

[15] Eghbali M, Safari R, Nazari F and Adboli S. The effects of reflexology on chronic low back pain intensity in nurses employed in hospitals affiliated with Isfahan University of Medical Sciences. Iranian Journal of Nursing and Midwifery Research 2012; 17(3): 239-243.

[16] Mogren IM, Pohjanen Al. Low back pain and pelvic pain during pregnancy: prevalence and risk factors. Spine. 2005; 30 (8):983-91.

[17] Yang HL, Chen XP, Lee KC, Fang FF, Chao YF. The effects of a warm water-water footbath on relieving fatigue and insomnia of gynaecologic cancer patients on chemotherapy. Cancer Nursing 2010; 33 (6); 454-60.

[18] Enzer, S. Maternity reflexology manual. 2nd ed. England: Soul to Sole Reflexology Limited.2004

[19] Tiran D. Reflexology in pregnancy and childbirth. 2010; London: Churchill Livingstone Elsevier 
[20] Close C. A pilot randomised controlled trial investigating reflexology in the management of low back and/ or pelvic during pregnancy, unpublished thesis $2015 ; 188-205$.

[21] Farrar JT, Portenoy RK, Berlin JA, Kinman J, Strom BL. Defining the clinically important difference in pain outcome measures. Pain 2000;88:287 -294.

[22] Ostelo RW, Deyo RA, Stratford P, Waddell G. Interpreting change scores for pain and functional status in low back pain: towards international consensus regarding minimal important change. Spine 2008; 33(1):90-4.

[23] Roland M, Fairbank J. The Roland-Morris Disability Questionnaire and the Oswestry Disability Questionnaire. Spine 2000; 25; 3115-3124.

[24] Mollart L. Single-blind trial addressing the differential effects of two reflexology techniques versus rest, on ankle and foot oedema in late pregnancy. Complementary Therapies in Nursing and Midwifery 2003; 9 (4): 203-208.

[25] Kvorning N, Holmberg C, Grennert L, Aberg A and Akeson J 2004.Acupuncture relieves pelvic and low back pain in late pregnancy. Acta Obstetricia et Gynecologica Scandinavica 2004; 83(3): 246-250. 
[26] Lund L, Lundenberg T, Lonnberg L. and Svenson E. Decrease in pregnant women's pelvic pain after acupuncture: a randomised controlled single-blind study. Acta Obstetricia et Gynecologica Scandinavica 2006; 85: 12-19.

[27] Miyazato K. and Matsukawa, K. Decreased cardiac parasympathetic nerve activity of pregnant women during foot baths. Japan Journal of Nursing Science 2000; 7, 65-75.

[28] Holt J, Lord U, White A, O'Neill N, Shaw S and Barton A. The effectiveness of foot reflexology in inducing ovulation: a sham-controlled randomized trial. Fertility and Sterility $2009 ; 91,6,2514-2519$.

[29] McCullough JEM, Liddle SD, Sinclair M, Close C, Hughes CM. The Physiological and Biochemical Outcomes Associated with a Reflexology Treatment: A Systematic Review. Evidence-Based Complementary and Alternative Medicine 2014; Available online at: http://www.hindawi.com/journals/ecam/2014/502123/cta/ (accessed $14^{\text {th }}$ June 2014) [30]Katz NP, Florence CP, Evan Ekman Determining the clinical importance of treatment benefits for interventions for painful orthopedic conditions, Journal of Orthopaedic Surgery and Research 2015, 10:24

[31] Kammers MPM, De Vignemont F and Haggard P. Cooling the Thermal Grill Illusion through Self-Touch. Current Biology 2010; 20, 1-4. 
[32] Vermani E, Mittal R, Weeks A. Pelvic girdle pain and low back pain in pregnancy: a review, Pain Practice 2010; 10 (1) 60-71.

[33] Field T, Diego M, Hernandez-Reif M, Medina L, Delgado J and Hernandez A. Yoga and massage therapy reduce prenatal depression and prematurity. Journal of Bodywork Movement Therapy, 2012; 16(2): 204-209.

[34] Martins RF, Pinto e Silva J.L. Treatment of pregnancy-related lumbar and pelvic girdle pain by the yoga method: a randomized controlled study. Journal of Alternative and Complementary Medicine 2014; 20(1):24-31.

[35] McCullough, J.E.M, Hughes, C.M., Sinclair, M (2014) Complementary and Alternative Medicine in the management of low back and/ or pelvic pain in pregnancy, International Congress of Midwives Conference, Prague, Czech republic, 3rd June. 
